\title{
RENTABILIDADE E CUSTO DA ATIVIDADE LEITEIRA EM BOCAIÚVA - MG
}

\author{
LEITE JÚNIOR, Iran Ferreira ${ }^{1}$ \\ LOPES, Marcos Aurélio ${ }^{1}$
}

CARDOSO, Antônio Augusto Brion ${ }^{2}$

Recebido em: 2017.03.16

Aprovado em: 2017.12.08

ISSUE DOI: $10.3738 / 1982.2278 .2722$

RESUMO: Objetivou-se, com esta pesquisa, estimar o custo de produção e analisar a rentabilidade da atividade leiteira de um sistema de produção no município de Bocaiuva, norte de Minas Gerais. Pretendeu-se, ainda, identificar os componentes que exerceram maiores representatividades sobre os custos finais da atividade, bem como, em relação à receita total, e estimar o ponto de equilíbrio. Os dados utilizados foram coletados, com anotações mensais do produtor em um caderno disponibilizado pelo Programa Minas Leite, durante o período de janeiro a dezembro de 2015. O processamento dos dados e a análise da rentabilidade foram realizadas utilizando a planilha Custo de Produção Para Cursistas da EMATER, considerando a margem bruta, a margem líquida e o resultado (lucro ou prejuízo) como indicadores de eficiência econômica. Os itens componentes do custo operacional efetivo que exerceram maiores representatividades foram em ordem decrescente: Alimentação, mão de obra, energia, sanidade, impostos fixos, despesas diversas, ordenha e inseminação artificial. Na análise econômica, o sistema apresentou margem líquida positiva e resultado negativo, indicando uma situação de prejuízo; porém, há possibilidade de manutenção na atividade no médio prazo e de reversão, se tomadas as providências para corrigir os pontos falhos.

Palavras-chave: Análise de rentabilidade. Bovinocultura de leite. Custo de produção. Ponto de equilíbrio.

SUMMARY: The objective of this research was to estimate the cost of production and to analyze the profitability of the dairy activity of a production system in the municipality of Bocaiuva, northern Minas Gerais. It was also intended to identify the components that exerted greater representativity on the final costs of the activity, as well as, in relation to total revenue, and estimate the break-even point. The data used were collected, with monthly notes of the producer in a notebook made available by the "Minas Leite" Program, during the period from January to December 2015. Data processing and profitability analysis were performed using the Production Costing For students EMATER, considering gross margin, net margin and profit or loss as indicators of economic efficiency. The components of the effective operational cost that exercised the greatest representativity were, in descending order: Food, labor, energy, sanitation, fixed taxes, miscellaneous expenses, milking and artificial insemination. In the economic analysis, the system presented net positive margin and negative result, indicating a situation of loss; However, there is a possibility of maintaining the activity in the medium term and reversion, if steps are taken to correct the flaws.

Keywords: Break-even point. Cost of production. Dairy cattle. Profitability analysis.

\section{INTRODUÇÃO}

Inserido em um novo cenário onde o concorrente não é apenas o vizinho, as atividades agropecuárias passam a fazer parte de um sistema complexo que vem exigindo do produtor uma visão mais abrangente e profissional. Com base nisso, a sua atividade deve ser encarada como um negócio que precisa gerar resultados positivos para sua manutenção e crescimento, porém, pouco adiantará se a medição desses resultados for realizada de forma amadora e empírica como ocorre em muitos casos.

Para Cardoso et al. (2016), há uma necessidade urgente de moderniar o sistema produtivo brasileiro devido a pressão cada vez maior para o uso intensivo das propriedades. No Brasil, muitos

\footnotetext{
${ }^{1}$ Universidade Federal de Lavras - UFLA

${ }^{2}$ Universidade Federal de Juiz de Fora - Campus Governador Valadares
} 
empresários rurais não têm conseguido gerir seus empreendimentos com a agilidade e a eficiência necessárias para mantê-los em situação competitiva, fruto de anos e anos de amadorismo na condução dos negócios. Lopes et al. (2011), afirmam que diante da nova ordem econômica, assim como a indústria, comércio e serviços, o produtor rural deve ter uma nova visão da administração de seus negócios.

Auad et al. (2010) afirmam que atualmente, no cenário mundial, o agronegócio tem sido indicado como o principal fator para o desenvolvimento comercial e industrial das nações, porém, para que haja sucesso nisso, é necessário o correto gerenciamento das suas atividades, ou seja, o modelo a ser adotado deve ir além de sistemas extrativistas, desta forma, torna-se urgente haver mudanças significativas na gestão.

Diante deste cenário, é imperativo afirmar que, independente do tamanho do negócio, não há margem para erros; é preciso ter uma gestão profissional e eficiente e, além de tudo, que tenha capacidade de realizar um planejamento adequado para sobreviver às intempéries mercadológicas. Cardoso et al. (2016) completam dizendo que uma gestão de forma profissional se faz necessária não só do ponto de vista do mercado, mas também para que o produtor conheça o seu negócio e assim consiga identificar os pontos positivos e negativos da sua atividade possibilitando assim maior assertividade na tomada de decisões.

Na visão de Megliorini (2012), para atender a demanda informacional dos gestores, conhecer custos é condição essencial para gerir uma empresa, independente do tipo. Lopes et al. (2004) afirmam que um sistema eficiente de custo de produção de leite é fundamental para se obter informações necessárias na tomada de decisões rápidas. Ainda na visão desses autores, a estimativa do custo de produção propiciará ao produtor informações muito importantes que o levarão a tomar decisões com relação às despesas e/ou ao volume de produção para manter uma atividade ou descontinuá-la.

Ferreira et al. (2016) afirmam que controlar e avaliar os custos de produção devem fazer parte do escopo de gestão financeira de uma propriedade rural. Segundo Iudícibus (2015) para se calcular o resultado de uma atividade, é preciso conhecer os custos desta atividade, no caso a pecuária leiteira não é diferente, ou seja, o produtor deve administrar o seu sistema de produção como uma empresa e para que ele tenha conhecimento de quanto lhe custa produzir aquele bem (leite, neste caso específico). Reis et al. (2001) afirmam que pelo fato de não ser possível controlar o preço de venda do seu produto, pois este é determinado pelo mercado, torna-se imperativo ter o controle sobre as variáveis que são possíveis de controlar, no caso, os custos de produção, ou seja, isto é uma estratégia para tornar o produto competitivo, além de se manter competitivo no mercado.

Apesar dos custos de produção na atividade leiteira ser largamente discutido em diversos periódicos e regiões, ainda não se tem registros de estudos realizados no Norte de Minas Gerais. Diante do contexto, o presente estudo buscou responder o seguinte questionamento: Qual o custo de produção do leite e qual a rentabilidade de uma propriedade produtora de leite? Objetivou-se com esta pesquisa estimar o custo de produção e analisar a rentabilidade da atividade leiteira, identificando o ponto de equilíbrio e os componentes que exerceram maiores representatividades nos custos finais além do impacto causado por eles, para tanto, foi realizado um estudo de caso em um sistema de produção de leite localizado em Bocaiúva - MG.

\section{MATERIAL E MÉTODO}

A pesquisa caracteriza-se como exploratória, que conforme definido por Gil (2008) tem como objetivo proporcionar maior familiaridade com o problema, com vistas a torná-lo mais explícito. Quanto a sua característica, trata-se de uma pesquisa qualitativa que para Godoy (1995), caracteriza-se pelo contato 
direto e prolongado do pesquisador com o ambiente estudado. Especificamente trata-se de um estudo de caso que segundo Yin (2013) é uma estratégia de pesquisa que compreende um método que abrange tudo em abordagens especificas de coletas e analise de dados.

A pesquisa abrangeu o período de janeiro a dezembro de 2015 e, considerou duas etapas diferentes no levantamento das informações. Na primeira etapa, foi realizado o inventário completo dos bens da propriedade estudada, para apurar valor e vida útil de cada ativo. Nas situações em que o pecuarista não dispunha de informações referentes ao valor e à data de aquisição, para a estimativa dos valores atualizados e da vida útil restante, foi adotado o critério proposto por Lopes et al. (2004). Cada benfeitoria foi medida, sendo avaliado e classificado seu estado de conservação e registrado um resumo no memorial descritivo, objetivando auxiliar na estimativa do valor atualizado. Em função da área, do estado de conservação e do padrão de acabamento, foi estimado um valor por $\mathrm{m}^{2}$ de construção. $\mathrm{O}$ valor atualizado foi produto do valor do $\mathrm{m}^{2}$ pela área da benfeitoria (LOPES et al., 2004).

$\mathrm{Na}$ segunda etapa, foram considerados os dados referentes ao fluxo de caixa, anotados pelo produtor, durante o ano de 2015. As anotações foram feitas no caderno de registro e coleta periódica de dados para avaliação de desempenho da atividade. Este caderno contempla o registro de dados referente ao manejo reprodutivo do rebanho, movimentação do rebanho, controle leiteiro, qualidade do leite e fluxo de caixa, conforme recomendação do Programa Minas Leite, sendo acompanhado pela EMATER-MG (SEAPA, 2016). As informações foram cadastradas na planilha Custo de produção disponibilizada pela EMATER (LOPES, 2016), utilizada para o lançamento das receitas e despesas oriundas da propriedade para posterior análise dos resultados. Essa planilha permite a estimativa do custo operacional efetivo (COE), do custo operacional total (COT) e do custo total. Para calcular a rentabilidade 1, foi utilizada a fórmula: rentabilidade $1(\%)$ = resultado / (total imobilizado + custo operacional efetivo) x 100 (SEBRAE, 1998). Para calcular a rentabilidade 2 , de cada propriedade, utilizou-se a fórmula: rentabilidade $2(\%)=$ margem líquida / (total imobilizado + custo operacional efetivo) x 100, conforme Lopes et al. (2011).

Para calcular a lucratividade 1 foi utilizada a fórmula: lucratividade $1(\%)=($ resultado / receita total) x 100 (SEBRAE, 1998). A lucratividade 2 foi calculada pela fórmula: lucratividade $2(\%)=$ (margem líquida / receita total) x 100 (LOPES et al., 2011)

No cálculo da renumeração do capital aplicou-se a taxa de poupança de 6,00\% ao ano e, para a renumeração da terra, optou-se pelo valor de arrendamento praticado na região, que foi de $1 \mathrm{~kg}$ de leite/ha/dia. Os itens que compõem o custo operacional efetivo de produção do leite foram divididos em grupos: mão de obra, alimentação, sanidade, inseminação artificial, ordenha, impostos fixos, energia e despesas diversas (LOPES et al., 2004).

Para evitar duplicidade de lançamento de despesas, a análise não considerou a depreciação de matrizes, uma vez que o sistema avalia o custo de produção da atividade como um todo e os custos de cria e recria de fêmeas de reposição, assim como os de manutenção de vacas secas, também foram contemplados no estudo (LOPES et al., 2004).

Os dados utilizados no presente estudo foram provenientes do sistema de produção de leite de uma propriedade localizada no município de Bocaiuva, região Norte de Minas Gerais.

Os bovinos jovens, em fase de recria, são alimentados no período da seca, com volumoso de bagaço de cana de açúcar e vinhoto, oriundos da produção artesanal de cachaça, corrigidos com o proteinado fornecido à vontade em cocheiras. Existe uma integração de atividades com o aproveitamento dos resíduos da produção de cachaça que anteriormente eram lançadas na natureza. A alimentação das matrizes no período seco é baseada no sistema EPAMIG de alimentação de vacas mestiças leiteiras, utilizando a mistura nitromineral para a correção de cana de açúcar (Saccharum officinarum) picada. As pontas da cana, descartadas na produção de cachaça, são aproveitadas na alimentação de matrizes leiteiras 
de menor potencial produtivo ou em final de lactação. Utiliza-se uma mistura de aproximadamente $30 \%$ desse material picado no volumoso de cana de açúcar.

Existe uma área de seis hectares implantadas no sistema de integração lavoura pecuária e floresta (ILPF), utilizada no momento para pastejo do rebanho de recria e o eucalipto se encontra em porte adequado para corte.

No último ano, foi implantado uma gleba de 1,80 hectares de pastagem Braquiaria brizantha Marandú, dividida em 32 piquetes, irrigados por aspersão convenciona. Esta pastagem é utilizada na alimentação das matrizes, com pastejo nos veranicos e nos períodos pré e pós seco, diminuindo, assim, o período de fornecimento de volumoso em cocheiras.

O rebanho existente é caracterizado como mestiço, com grau de sangue em torno de $1 / 2 \mathrm{HZ}$. Utiliza tecnologia de inseminação artificial com sêmen de touros da raça holandêsa para vacas azebuadas e sêmen de touro da raça girolando (3/4) para vacas com grupo genético acima de $1 / 2 \mathrm{HZ}$. Um touro gir leiteiro, registrado é usado para repasse das matrizes que não emprenham com a inseminação.

A propriedade é participante do Projeto de Adequação Socioeconômica e ambiental onde, através da metodologia ISA (Indicadores de Sustentabilidade em Agroecossistemas), foram identificados pontos de estrangulamentos nos aspectos socioeconômicos e nos aspectos ambientais que foram e/ou estão sendo corrigidos pelo proprietário e sua família.

Com tanta diversidade de gastos e metodologias de trabalho variadas, sendo algumas de cunho sustentável, cabe estimar o custo de produção e a rentabilidade dessa atividade, base para a tomada de decisão no negócio leite na Fazenda São Pedro.

Os índices produtivos e econômicos foram comparados por meio de análises descritivas, utilizando-se o aplicativo MS Excel ${ }^{\circledR}$, e agrupados em tabelas, objetivando realizar melhores comparações, discussões e apresentação dos resultados (LOPES et al., 2004).

\section{RESULTADO E DISCUSSÃO}

O presente estudo foi realizado em uma propriedade familiar localizada no município de Bocaiúva, região norte de Minas Gerais. Apesar de produzir apenas 250 litros de leite diariamente, o produtor registra em um caderno os dados referentes ao controle leiteiro, manejo reprodutivo, movimentação do rebanho, qualidade do leite e fluxo de caixa e suas decisões são baseadas apenas nestes registros. O proprietário desconhece o seu custo de produção, bem como a representatividade das despesas no seu negócio. A compra de máquinas e a realização de benfeitorias são feitas sem que haja um levantamento da viabilidade do investimento, seja para cálculo do retorno financeiro do investimento, seja para identificar e remuneração do capital investido.

Os dados apresentados referem-se ao período de janeiro de 2015 a dezembro de 2015 e estão apresentados na Tabela 1. Esses recursos foram utilizados na discussão dos resultados alcançados nesta pesquisa. 
Tabela 1 - Recursos disponíveis na propriedade de agricultura familiar estudada, no município de Bocaiuva-MG (período de 01/01/2015 a 31/12/2015).

\begin{tabular}{lcc}
\hline \multicolumn{1}{c}{ Especificação } & Valores (R\$) & Valores (\%) \\
\hline Valor do patrimônio em terra & $400.000,00$ & 56,76 \\
Valor do patrimônio sem terra & $304.815,60$ & 43,24 \\
Valor em benfeitorias & $47.100,00$ & 6,68 \\
Valor em equipamentos & $35.830,00$ & 5,08 \\
Valor em ferramentas & 385,60 & 0,05 \\
Valor em implementos & 8000,00 & 1,14 \\
Valor em máquinas & $32.500,00$ & 4,61 \\
Valor em veículos & $40.000,00$ & 5,68 \\
Valor em semoventes & $1.500,00$ & 0,21 \\
Valor em animais & $135.500,00$ & 19,22 \\
Valor em móveis & $4.000,00$ & 0,57 \\
Valor total imobilizado & $704.815,60$ & 100,0 \\
Área (ha) & 80,0 & \\
Valor do patrimônio em terra/ha (R\$) & $5.000,00$ & \\
Total imobilizado / ha $(\mathbf{R} \mathbf{\text { ) }}$ & $8.810,20$ & \\
\hline
\end{tabular}

Fonte: Dados da pesquisa

Nota-se que o valor do patrimônio em terra corresponde a 56,76\% do valor total do imobilizado, confirmando os dados do SEBRAE (2006), que identificaram, em entrevista a produtores de leite do estado de Minas Gerais, 70,67\% do capital investido na atividade leiteira estão alocados em patrimônio territorial. Por outro lado, Santos (2010) afirma que em sistemas de semiconfinamento, o valor de 31,10\% do total do patrimônio são investidos em terra. Explica-se essa diferença a existência de grande ociosidade no uso da terra nos sistemas de produção analisados pelo SEBRAE (2006) e também identificado neste estudo de caso, em discordância aos resultados apresentados por Santos (2010), da análise de um sistema mais intensivo de produção.

O valor investido no rebanho foi o item com maior representatividade do "patrimônio sem terra", seguido pelas benfeitorias, veículos, equipamentos, máquinas, implementos, móveis, animal de serviço e ferramentas (Tabela 1). Essa situação se explica pelo fato do rebanho bovino ser composto por 57 cabeças de linhagem leiteira e não ser praticado a venda de fêmeas na fase de cria ou recria. Essa expressividade demonstra a necessidade de cuidados relacionados à aquisição de animais, manejo alimentar e nutricional, reprodução e uso e ocupação das pastagens para, assim, conseguir obter um maior e mais rápido retorno do capital. Esse tipo de investimento é considerado custo fixo, sendo recomendado eficiência em todos os indicadores, principalmente os produtivos, para que possam ser 'diluídos', refletindo menos no custo total, conforme enfatizado por Lopes et al. (2011b).

$\mathrm{O}$ valor do capital imobilizado por hectare foi de $\mathrm{R} \$ 8.810,20$, quantia considerado baixa quando comparada com um estudo realizado por Lopes et al. (2011b) na região de Varginha, que encontrou R $\$ 44.558,26$. No entanto, o imobilizado / ha é considerado alto se comparado com o diagnóstico do SEBRAE (2006), realizado no estado de Minas Gerais, que encontrou valores de $\mathrm{R} \$ 6.723,78$, em sistemas de produção com mais de 1000 litros de leite/dia. Essas diferenças podem estar relacionadas aos preços de terras nas diferentes regiões do país, incorporação de tecnologias, taxa de lotação, investimento em estruturas e valores dos animais. A tabela 2 apresenta um resumo da análise de rentabilidade da atividade leiteira. 
Tabela 2 - Resumo da análise de rentabilidade da propriedade de agricultura familiar estudada, no município de Bocaiuva-MG (período de 01/01/2015 a 31/12/2015)

\begin{tabular}{|c|c|}
\hline Especificação & Valor \\
\hline Receitas (R\$) & $94.570,13$ \\
\hline Leite $(\mathrm{R} \$)$ & $82.160,50$ \\
\hline Animais $(\mathrm{R} \$)$ & $9.202,00$ \\
\hline Queijo & $3.207,63$ \\
\hline Custo operacional total (COT) & $83.781,54$ \\
\hline Custo operacional efetivo (COE) (R\$) & $67.453,61$ \\
\hline Custo com depreciação (R\$) & $5.767,93$ \\
\hline Mão de obra familiar (R\$) & $10.560,00$ \\
\hline Custo total (CT) & $145.791,73$ \\
\hline Custos fixos $(\mathrm{CF})$ & $56.337,40$ \\
\hline Remuneração da terra $(\mathrm{R} \$)$ & $30.230,53$ \\
\hline Remuneração do capital investido (R\$) & $18.288,94$ \\
\hline Impostos fixos $(\mathrm{R} \$)$ & $2.050,00$ \\
\hline Depreciação (R\$) & $5.767,93$ \\
\hline Custos variáveis $(\mathrm{CV})$ & $89.454,33$ \\
\hline Custo operacional efetivo (s/impostos) (R\$) & $65.403,61$ \\
\hline Mão de obra familiar (R\$) & $10.560,00$ \\
\hline Remuneração do capital de giro $(\mathrm{R} \$)$ & $13.490,72$ \\
\hline Margem bruta / kg de leite & 0,33 \\
\hline Margem líquida / kg de leite & 0,138 \\
\hline Resultado (lucro ou prejuízo) / kg de leite & $-0,62$ \\
\hline Lucratividade $1(\%)$ & $-54,16$ \\
\hline Rentabilidade $1(\%)$ & $-6,63$ \\
\hline Lucratividade $2(\%)$ & 11,41 \\
\hline Rentabilidade $2(\%)$ & 1,40 \\
\hline Variação patrimonial do rebanho & $21.000,00$ \\
\hline Quantidade de kg de leite comercializada & 82.458 \\
\hline Quantidade de kg de leite consumida & 380 \\
\hline Quantidade total de $\mathrm{kg}$ de leite produzido & 82.838 \\
\hline Custo operacional total $(\mathrm{R} \$) / \mathrm{kg}$ de leite & 1,02 \\
\hline Custo operacional efetivo $(\mathrm{R} \$) / \mathrm{kg}$ de leite & 0,82 \\
\hline Custo total $(\mathrm{R} \$) / \mathrm{kg}$ de leite & 1,77 \\
\hline Custo fixo $(\mathrm{R} \$) / \mathrm{kg}$ de leite & 0,68 \\
\hline Custo variável $(\mathrm{R} \$) / \mathrm{kg}$ de leite & 1,08 \\
\hline Preço médio do kg leite $(\mathrm{R} \$)$ & 1,04 \\
\hline
\end{tabular}

Lucratividade 1: resultado / receita total; Lucratividade 2: margem líquida / receita total; Rentabilidade 1: resultado /(custo operacional efetivo + imobilizado total); Rentabilidade 2: margem líquida /(custo operacional efetivo + imobilizado total); Variação patrimonial do rebanho= valor final - valor inicial do rebanho.

Fonte: Dados da pesquisa

A receita total é constituída pela venda de leite, (86,88\% do faturamento total), animais, $(9,73$ $\%)$ e queijo, (3,39 \%), sendo esta última uma receita não usual, pois surgiu apenas como uma oportunidade de mercado (Tabela 2). Diante do exposto, percebe-se que o faturamento foi suficiente 
para cobrir o custo operacional total (COT), que representou $88,6 \%$ dos gastos do negócio nesta propriedade, ou seja, a receita foi suficiente para cobrir as despesas relacionadas a alimentação do rebanho, mão de obra, sanidade, reprodução, ordenha, energia e despesas diversas (custo operacional efetivo), além do custo com depreciação e a retirada para manutenção familiar. Por outro lado, a receita obtida não foi suficiente para cobrir o custo total (CT) que a superou em 54\%, mesmo considerando o valor de $\mathrm{R} \$ 10.788,59$ que sobrou após a subtração do custo operacional total, o que demonstra que a atividade não está sendo viável a longo prazo.

Comparando-se a receita advinda da venda do leite $(90,27 \%)$ e da venda de animais $(9,73 \%)$, os percentuais estão acima para o leite e abaixo para a venda de animais, respectivamente, em relação aos resultados encontrados por Lopes et al. (2004), 86,94\% e 12,45\% e Lopes et al. (2005), 80,98\% e $16,02 \%$. O percentual encontrado para a venda de animais está abaixo dos resultados encontrados por Lopes et al. (2003) e Moraes et al. (2004) que foram 12,15\% e 25,90\%, respectivamente.

Não houve a receita com a venda de subproduto (esterco) pois, o mesmo é utilizado na adubação de pastagens e capineiras. $\mathrm{O}$ fato desse subproduto ser utilizado na própria atividade, induz a pensar na perda de receita, que é abolida quando se considera a redução das despesas com aquisição de adubos (LOPES et al., 2004). Para De Sá Mota et al. (2016), os adubos orgânicos possuem um custo mais baixo, fato este que leva, principalmente, as pequenas propriedades a utilizar desta tecnologia, além de ser uma tecnologia recomendada para fazer o uso e conservação de solos.

No custo total estão incluídos os custos fixos e os variáveis, sendo que os fixos contemplam a remuneração da terra, a remuneração do capital investido, os impostos fixos e a depreciação. No tocante a remuneração do capital investido cabe o entendimento do conceito de custo de oportunidade, pois de acordo com Pindyck e Rubinfeld (2013), são custos associados às oportunidades de investimento deixadas de lado pelo proprietário para se investir em algo mais rentável. Os custos variáveis contemplam os gastos com o custo operacional efetivo (s/impostos - considerados fixos), a mão de obra familiar e a remuneração do capital de giro.

Em relação aos indicadores de rentabilidade apresentados na tabela 2, percebe-se que a margem bruta e a líquida foram positivas, demonstrando certa estabilidade no negócio, por ser a receita bruta suficiente para arcar com o custo operacional efetivo e o operacional total, respectivamente. Por outro lado, o indicador "resultado" foi negativo, com prejuízo no valor de $\mathrm{R} \$ 51.221,60$, que caracteriza um problema de descapitalização, a longo prazo. Esse problema pode ser resolvido, muitas vezes, por um profissional habilitado para diagnóstico situacional e propostas corretivas. Situação de fragilidade confirmada, quando se observa os indicadores: lucratividade 1 e rentabilidade 1 negativos. No entanto, a lucratividade 2 e a rentabilidade 2 apresentaram valores positivos, uma vez que utiliza uma metodologia de cálculo baseado na margem líquida (LOPES et al., 2011), mas não exprime a ideia de sustentabilidade a longo prazo. Essa questão exige muito cuidado, pois existe um consenso entre os produtores de leite, talvez pela dificuldade de sobrevivência na atividade, que se a receita for suficiente para pagar as despesas operacionais e cobrir as despesas da família, o negócio está apresentando bons resultados.

Comparando o resultado com um sistema que utiliza rebanho com grupo genético semelhante, confirma-se a inferioridade, onde, em um estudo econômico com gado mestiço F1 holandês-zebu, Moraes et al. (2004) encontraram uma lucratividade média de 28,9\%, sendo a venda de bezerros desaleitados responsável por $25 \%$ da receita total. Tal fato pode ser explicado quando é analisado o histórico do rebanho, que ainda não está estabilizado, sendo a receita de animais, oriunda da venda de bezerros e vacas descartadas consideradas problemáticas.

Resultado negativo indicou que a receita obtida não foi suficiente para a remuneração da terra e do capital investido, que são considerados custos fixos. Os custos fixos sempre vão permanecer 
constantes, se não houver aquisição ou venda de bens (LOPES et al., 2004). A subutilização da terra, a valorização do patrimônio, motivada pela proximidade da zona urbana, e a existência de uma estrutura de produção herdada dos genitores, faz com que onere ainda mais os gastos com a intensificação dos custos fixos. A recomendação para obter resultado positivo, parte do princípio da necessidade da diluição desses custos fixos, com o aumento da produção de leite e de bezerros.

A Tabela 2 também demonstra uma situação referente ao mercado do leite. A atividade foi remunerada com o preço do leite em $\mathrm{R} \$ 1,04$, um pouco acima da média do preço do leite em Minas Gerais, na ordem de $\mathrm{R} \$ 1,0315$, de acordo com a CEPEA (2016). No entanto, não foi suficiente para cobrir o custo variável e o custo total, que apresentou valores de $\mathrm{R} \$ 1,08$ e $\mathrm{R} \$ 1,77$, respectivamente.

A despesa com alimentação foi o item com maior representatividade no custo operacional efetivo (48,70\%) quando comparado com as outras despesas (Tabela 3). Essa divisão das despesas permite fazer um monitoramento no sistema de produção de leite, auxiliando o técnico e o produtor em uma análise mais detalhada (LOPES et al., 2007). Boa parte dessa porcentagem é oriunda de insumos utilizados no balanceamento de ração concentrada dentro da propriedade. Esse resultado é considerado bom, abaixo da média encontrada (59,65\%) pela maioria dos pesquisadores (BERG e KATSMAM, 1998; LOPES et al., 2004; e CARVALHO et al., 2009). Durante o período da pesquisa, as vacas em lactação receberam volumosos de pastagem Braquiarão (Brachiaria brizantha $c v$ Marandu) em piquetes rotacionados irrigados, onde a relação concentrado/ produção de leite variou ao longo do ano de $1 \mathrm{~kg}$ de concentrado para $3 \mathrm{~kg}$ de leite produzidos, acima de 5 litros e acima de 8 litros de leite, de acordo com a capacidade animal e a qualidade do volumoso disponível. Provavelmente, essa tecnologia permitiu melhora significativa nesse índice, mas, ainda dentro de valores apresentados por outros estudos como Lopes et al. (2004 e 2007) e Rodrigues Filho et al. (2002), que encontraram alimentação com porcentagens entre $41,87 \%$ a $60,95 \%$ dentro das despesas do custo operacional efetivo.

Tabela 3 - Representatividade de cada grupo de despesas no custo operacional efetivo (COE) da propriedade de agricultura familiar estudada, no município de Bocaiuva-MG (período de 01/01/2016 a $31 / 12 / 2015)$.

\begin{tabular}{lcc}
\hline Especificação & $\mathbf{R}$ & $\mathbf{\%}$ \\
\hline Alimentação & $32.850,19$ & 48,70 \\
Energia & $7.357,01$ & 10,90 \\
Mão-de-obra & $16.200,00$ & 24,02 \\
Ordenha & $1.250,71$ & 1,85 \\
Sanidade & $5.563,00$ & 8,25 \\
Inseminação artificial & 841,20 & 1,25 \\
Impostos fixos (ITR, IPVA, licenc. e seguro do veículo) & $2.050,00$ & 3,04 \\
Despesas diversas & 1341,50 & 1,99 \\
\hline Total & $67.453,61$ & 100,00 \\
\hline
\end{tabular}

Fonte: Dados da pesquisa

O segundo item de maior representatividade no custo operacional efetivo foi as despesas com mão de obra (24,02\%), considerando o salário e os encargos financeiros de um funcionário contratado, além das despesas com mão de obra eventual. Esse percentual está acima do encontrado por Lopes et al. (2007) 17,16\%, por Lopes et al. (2005) (19,48\%), por Gomes (1997) (20\%), demonstrando que parte da mão de obra está ociosa ou mal utilizada. O grupo energia contemplou as despesas de energia elétrica e combustíveis e foi o terceiro item mais representativo $(10,9 \%)$ no custo operacional efetivo; a energia 
elétrica representou 58\% do custo desse grupo. Provavelmente o nível tecnológico adotado nessa propriedade tenha contribuído para aumentar as despesas de energia elétrica, que além de contar com ordenhadeira mecânica, tanque de expansão e desintegradores, utiliza um sistema de irrigação por aspersão nos canaviais e de uma gleba de piquetes rotacionados. Esse resultado é considerado alto se comparado com outros estudos. Lopes et al. (2011) encontraram média de 6,74\% dos gastos atribuído a energia em um estudo de rentabilidade no município de Nazareno-MG, em quatro sistemas de produção.

O grupo sanidade aparece em $4^{\circ}$ lugar no ranking de maiores despesas, com 8,25\% do COE; valor muito acima do encontrado por Lopes et al., (2004), Lopes et al., (2011) e Franco Neto et al. (2009), de 3,91\%, 4,02\% e 1,25\%, respectivamente; e acima da média (5,97\%) encontrada no estudo de Berg e Katsman (1998). Do percentual encontrado, 59,8\% refere-se a produtos estimulantes à base de somatotropina bovina recombinante, adquiridos e administrados nas vacas em lactação durante o último semestre. A introdução desse tratamento ocorreu por conta e risco do produtor, sem buscar orientação técnica de profissional habilitado e sem avaliação dos resultados. Segundo Bauman et al. (1985), o bST atua na regulação da partição de nutrientes, direcionando-os para a produção de leite e também aumenta a eficiência de utilização desses nutrientes pela glândula mamária. Na ausência da disponibilidade de nutrientes, ou seja, caso as necessidades nutricionais dos animais não sejam atendidas, não haverá resposta em produção com o uso dessa tecnologia. Talvez por esse motivo, o uso do bST é associado a rebanhos de alta produção, nos quais existe um manejo de melhor qualidade. LOPES et al. (2004) enfatizaram a necessidade de um trabalho de educação, prevenção e conscientização dos produtores de leite sobre a importância da saúde animal. Impostos considerados fixos, como ITR, IPVA, licenciamento e seguro de veículo, representaram 3,04\% do custo operacional efetivo.

O grupo despesas diversas, que contempla despesas que não se enquadram nos demais grupos, como manutenção benfeitorias, máquinas e equipamentos, dentre outros, representou $1,99 \%$ do $\mathrm{COE}$, muito abaixo do encontrado por Lopes et al. (2007) e Lopes et al. (2011), nos valores de 13,47\% e $11,44 \%$, respectivamente. O resultado negativo (Tabela 2) pode ser a explicação da baixa porcentagem de despesas, consideradas diversas. Além de não remunerar o capital investido, o produtor adia a manutenção e reparos de benfeitorias, máquinas e equipamentos envolvidos com a atividade.

$\mathrm{O}$ grupo de despesas relacionadas à ordenha ficou em último lugar, representando 1,85\% do COE; porém, acima da média (1,74\%) encontrada na literatura e citado por Lopes et al. (2011). A aplicação de recursos financeiros na aquisição de papel toalha, detergentes, produtos para pré-dipping e pós-dipping, óleo para a bomba de vácuo, bem como peças para reposição, sabão em pó e outros, propiciou valores de contagem bacteriana abaixo de $20.000 \mathrm{UFC} / \mathrm{ml}$ e contagem de células somáticas abaixo de 400.000 células/ml, atendendo antecipadamente a instrução normativa 62, que trata da lei da qualidade do leite, justificando assim, este gasto.

Tabela 4 - Índices técnicos e gerenciais da propriedade de agricultura familiar estudada, no município de Bocaiuva-MG (período de 01/01/2015 a 31/12/2015).

(Continua)

\begin{tabular}{lc}
\hline Especificação & Valor \\
\hline Depreciação / COT (\%) & 6,88 \\
COE / COT (\%) & 80,51 \\
Mão-de-obra familiar / COT (\%) & 12,60 \\
Custo Fixo / Custo Total (\%) & 38,64 \\
Custo Variável / Custo Total (\%) & 61,36 \\
Depreciação / Custo Total (\%) & 3,96
\end{tabular}


Tabela 4 - Índices técnicos e gerenciais da propriedade de agricultura familiar estudada, no município de Bocaiuva-MG (período de 01/01/2015 a 31/12/2015).

(Conclusão)

\begin{tabular}{lc}
\hline Especificação & Valor \\
\hline Quantidade de vacas em lactação / ha (matrizes) & 18 \\
Quantidade de mão de obra (dia / homem) & 2 \\
Relação animais/mão de obra (cabeça / dia / homem) & 9 \\
Produção de leite / mão de obra (kg / serviço) & 113,47 \\
Produção de leite diária (kg de leite) & 226,95 \\
Produtividade vaca / dia (kg de leite) & 12,61 \\
Área destinada à atividade leiteira (ha) & 54,37 \\
Produção de leite/ha/ano (kg de leite) & $1.523,60$ \\
Ponto de equilíbrio (kg) & $*$ \\
\hline
\end{tabular}

COT: custo operacional total; COE: custo operacional efetivo; * não foi possível estimar devido o preço de venda do leite ser inferior ao do custo variável unitário.

Fonte: Dados da pesquisa

A relação depreciação / COT (Tabela 4) é um método indireto de medir a eficiência de utilização de recursos disponíveis para a atividade leiteira. O valor de 6,88\% é bem inferior aos 14,37\% e 14,25\%, encontrados por Lopes et al. (2004) e Franco Neto et al. (2009), respectivamente. Esse valor, embora menor do que aqueles encontrados na literatura, não demonstra uma eficiência desse sistema de produção, pois o resultado foi negativo. Essa baixa representatividade da depreciação pode estar ligado a falta de recursos para a atividade leiteira ou, ao alto custo operacional efetivo, tornando esse gasto de menor impacto.

A propriedade conta com 18 vacas em lactação, com mão de obra ocupada, relação vacas:homem, de 9:1 (Tabela 4). Esta relação encontrada é considerada muito baixa e reflete diretamente no custo da mão de obra (Tabela 3). Lopes et al. (2003) encontraram resultados insatisfatórios semelhantes, com relação vaca:homem de 7:1, sendo a mão de obra responsável por $25,81 \%$ do total das despesas operacionais efetivas. Jarret (1997) preconizou uma relação vaca:homem de 66:1 para sistemas de produção com 300 vacas. A produção de leite diária por mão de obra envolvida, de 113,47 kg (Tabela 4), está abaixo dos $246,12 \mathrm{~kg}$ obtidas por Schiffler et al. (1999) e acima dos $80 \mathrm{~kg}$ encontrados por Lopes et al. (2003). Para Ferreira e Miranda (2007), a produtividade da mão-de-obra é obtida dividindose a produção média diária pela quantidade média de trabalhadores na atividade leiteira. Deve ser superior a 150 litros/dia/empregado, para produção de leite a pasto. Para sistemas mais tecnificados precisa ser superior a 300 litros/dia/empregado.

A produção de leite foi de 1.523,60 kg de leite/ha/ano (Tabela 4), que corresponde a 4,17 kg de leite/ha/dia, muito inferior ao recomendado por Ferreira e Miranda (2007), que define como produção ideal para rebanhos mestiços um volume superior a $10 \mathrm{~kg} / \mathrm{ha} / \mathrm{dia}$. Essa sub utilização da terra na atividade de bovinocultura de leite é muito comum no estado de Minas Gerais (SEBRAE, 2006). Lopes et al. (2004) encontraram valores de $2.614 \mathrm{~kg}$ de leite/ha/ano, considerado, ainda, muito baixo quando comparado aos encontrados por Gomes (1997), Shiffler et al. (1999) e Lopes et al. (2003). A produção média diária de leite foi de 226,95 kg, com uma produtividade de 12,61 kg por matriz em lactação. Essa produtividade de leite supera a encontrada por Lopes et al. (2004) de 9,35 kg/matriz em lactação/dia. Essa quantidade é considerada satisfatória quando comparado com sistemas em regime de semiconfinamento, considerados mais eficientes, que encontraram 17,36;13,04; $16,46 \mathrm{~kg} / \mathrm{vaca} / \mathrm{dia}$ em três fazendas leiteiras (LOPES; SANTOS, 2013).

Um indicador importante na gestão de custos, é o ponto de equilíbrio, que segundo Santos e Pereira (2012), é a quantidade a ser comercializada para que receitas e custo total se igualem. No 
presente trabalho, não foi possível estimar o ponto de equilíbrio (Tabela 4), devido o preço do leite estar abaixo do custo variável unitário. Geralmente o preço do leite é definido pelo mercado, cabendo ao produtor a minimização dos custos de produção. Percebe-se que esforços devem ser concentrados neste sentido, aumentando a eficiência produtiva e consequentemente, otimizando, assim, as despesas operacionais efetivas (LOPES et al., 2004). A alimentação, mão de obra e energia (Tabela 3) contribuíram diretamente para o aumento do custo de produção. Deve ser feito um diagnóstico para identificar os pontos de estrangulamento para depois optar por diminuir, dentro das possibilidades, os custos fixos. Verificar a possibilidade de melhoria no preço do leite, se houver concorrência na região, bem como melhorar os índices zootécnicos visando o aumento da produtividade e da produção de leite, são alternativas para resolver esse problema.

\section{CONSIDERAÇÕES FINAIS}

Dentre os objetivos propostos, o presente estudo conseguiu calcular o custo de produção, bem como identificar os itens componentes do custo operacional efetivo que exerceram maiores representatividades na atividade leiteira, são eles em ordem decrescente: Alimentação, mão de obra, energia, sanidade, impostos fixos, despesas diversas, ordenha e inseminação artificial.

$\mathrm{Na}$ análise econômica, para a propriedade apresentou margem líquida positiva e resultado negativo, indicando que têm condições de continuar na atividade a médio prazo; porém, está se descapitalizando, com o futuro comprometido a longo prazo. A impossibilidade de estimar o ponto de equilíbrio, por ser o valor de venda menor que o custo variável unitário, resultando em uma margem líquida negativa, fato que evidencia a necessidade de esforços gerenciais buscando a melhoria no preço do leite comercializado e/ou a redução dos custos de produção.

\section{REFERÊNCIAS}

AUAD, A. M. et al. Manual de Bovinocultura de Leite. Brasília, DF: LK, 2010.

BAUMAN, D. E. et al. Responses of high-producing dairy cows to long-term treatment with pituitary somatotropin and recombinant somatotropin. Journal of dairy science, v. 68, n. 6, p. 1352-62, 1985.

BERG, H. V. D.; KATSMAN, T. Custos: comparando despesas na produção do leite. Boletim do Leite, Piracicaba, v. 5, n. 52, p. 3, 1998.

CARDOSO, A. A. B.et al. Aplicação do Balanced Scorecard como suporte às decisões gerenciais: estudo de caso em uma propriedade leiteira de grande porte. Revista Científica de Produção Animal, v. 17, n. 2, p. 103-113, 2016.

CARVALHO, F. de M.; RAMOS, O.E., LOPES, M. A. Análise comparativa dos custos de produção de duas propriedades leiteiras no município de Unaí-MG, no período de 2003 e 2004. Ciência e Agrotecnologia. V. 33, edição especial, p. 1705-1711. 2009.

CEPEA - Centro de Estudos Avançados em Economia Aplicada - ESALQ/USP. Valores nominais do leite - R\$/Litro. Disponível em: http://www.cepea.esalq.usp.br/leite . Acesso em 29 maio 2016.

DE SÁ MOTTA, I.et al. Experiências com o aproveitamento de resíduos diversos na produção de adubos orgânicos e substratos para mudas. Cadernos de Agroecologia, v. 10, n. 3, 2016. 
FERREIRA, B. G. C.; FREITAS, M. M. L.; MOREIRA, G. C. Custo operacional efetivo de produção de soja em sistema de plantio direto. Revista iPecege, v. 1, n. 1, 2016.

FERREIRA, A. M.; MIRANDA, J. E. C. Medidas de eficiência da atividade leiteira: índices zootécnicos para rebanhos leiteiros. Comunicado Técnico:54. Juiz de Fora, MG, EMBRAPA, 2007.

GIL, A. C. Métodos e técnicas de pesquisa social. 6 ed. São Paulo: Atlas, 2008.

GODOY, A. S. Introdução à pesquisa qualitativa e suas possibilidades. Revista de administração de empresas, v. 35, n. 2, p. 57-63, 1995.

GOMES, S. T. Indicadores de eficiência técnica e econômica na produção de leite. São Paulo: FAESP, 1997. $178 \mathrm{p}$.

IUDÍCIBUS, S. D. Teoria da contabilidade. 11 ed. São Paulo: Atlas, 2015.

JARRET, J. Produção de leite de qualidade. In: SIMPÓSIO INTERNACIONAL SOBRE PRODUÇÃO

INTENSIVA DE LEITE, 3., 1997, Belo Horizonte. Anais... Belo Horizonte: FMVZ/USP. 1997. p. 34-45.

MEGLIORINI, E. Custos: análise e gestão. 3 ed. Pearson Prentice Hall, 2012.

LOPES, M. A. Gestão na bovinocultura de leite. Lavras-MG, Centro de Educação á Distância - CEAD, UFLA, 2015.

LOPES, M. A., Planilha Custo de produção para cursistas da Emater. Centro de Educação à Distância - CEAD, Ambiente Virtual de Aprendizagem. Lavras-MG, UFLA, 2016.

LOPES, M. A.et al. Rentabilidade de um sistema de produção de leite tipo B: um estudo de caso com a raça Jersey no Estado de São Paulo. Revista Economia Rural. v. 14, n.1/2, p.11-15. 2003.

LOPES, M. A.et al. Efeito do tipo de sistema de criação nos resultados econômicos de sistemas de produção de leite na região de Lavras (MG) nos anos 2004 e 2005. Ciência Animal Brasileira, v.8, n.3, p. 359-371, jul.-set. 2007.

LOPES, M. A.; GOMIDE, D. R.; NETO, A. F.; SANTOS, G. dos. Resultados econômicos de um sistema de produção de leite na região de Varginha - Sul de Minas Gerais. Boletim de Indústria Animal, N. Odessa, v.68, n.1, p.007-015, jan/jun., 2011.

LOPES, M. A.et al.Controle gerencial e estudo da rentabilidade de sistemas de produção de leite na região de Lavras (MG), Ciência e Agrotecnologia, v. 28, n. 4, p. 883-892, 2004.

LOPES, M. A.et al. Resultados econômicos de sistemas de produção de leite com diferentes níveis tecnológicos na região de lavras, MG. Arquivo Brasileiro de Medicina Veterinária e Zootecnia, v.57, n.4, p. 485-493. 2005.

LOPES, M. A.; SANTOS, G. Análise da rentabilidade de fazendas leiteiras em regime de semiconfinamento com alta produção diária. Informações Econômicas, São Paulo, v.43, n.3, maio/jun. 2013.

LOPES, M. A.et al.Estudo da Rentabilidade de Sistemas de Produção de Leite no Município de NazarenoMG. Ciência Animal Brasileira, Goiânia, V.12, n.1, p. 58-69, 2011 b.

MORAES, A. C. A.; COELHO, S. G.; RUAS, J. R. M. Estudo técnico e econômico de um sistema de produção de leite com gado mestiço F1 Holandês-Zebu. Arquivo Brasileiro de Medicina Veterinária e Zootecnia, v.56, n.6, p. 745-749, 2004.

PINDYCK, R. ; RUBINFELD, D. L. Microeconomia. 8. ed. São Paulo: Makron Books, 2013. 
REIS, R. P.; MEDEIROS, A. L.; MONTEIRO, L. A. Custos de produção da atividade leiteira na região sul de Minas Gerais. Organizações Rurais e Agroindustriais, Lavras, v. 3, n. 2, p. 45-52, 2001

RODRIGUES FILHO, M.et al. Avaliação econômica do confinamento de novilhos de origem leiteira, alimentados com diferentes níveis de concentrado e de cama de frango. Revista Brasileira de Zootecnia, v. 31, n. $5,2002$.

SANTOS, G. Indicadores econômicos de diferentes sistemas de produção de leite com alto nível tecnológico em Minas Gerais. 2010. 228 f. Dissertação (Mestrado em Ciências Veterinárias) Universidade Federal de Lavras.

SANTOS, S. A., PEREIRA, H. J. (Org.). Criando seu próprio negócio: como desenvolver o potencial empreendedor. Brasília: Sebrae.2012.

SCHIFFLER, E. A.et al. de. Efeito da escala de produção nos resultados de produção de leite B no estado de São Paulo. Revista Brasileira de Zootecnia, Viçosa, v.28, n.2, p. 425-431, mar./abr. 1999.

SEBRAE - Serviço Brasileiro De Apoio Às Micro E Pequenas Empresas. Manual de Capacitação Rural. Goiânia, Sebrae, 1998.

SEBRAE- Serviço Brasileiro De Apoio Às Micro E Pequenas Empresas, Diagnóstico da pecuária leiteira do estado de Minas Gerais em 2005. Belo Horizonte: FAEMG, 2006. (Relatório de pesquisa).

SEAPA - Secretaria de Estado de Agricultura, Pecuária e Abastecimento, Programa Minas Leite. Disponível em: < www.agricultura.mg.gov.br/politica de privacidade/page/31-programas estruturadoresminas leite> Acesso em 09 mar. 2016.

YIN, R. K. Case study research: Design and methods. Sage publications, 2013. 
